\section{DIMENSIONAMENTO DE TUBULAÇÃO DE ÁGUA FRIA: ADAPTAÇÃO PARA NBR5626}

\author{
Modalidade: Materiais didáticos desenvolvidos
}

\section{ESTRUTURA}

Figura 1: Tabelas com os dados extraídos do Revit e com os cálculos e condições da NBR 5626

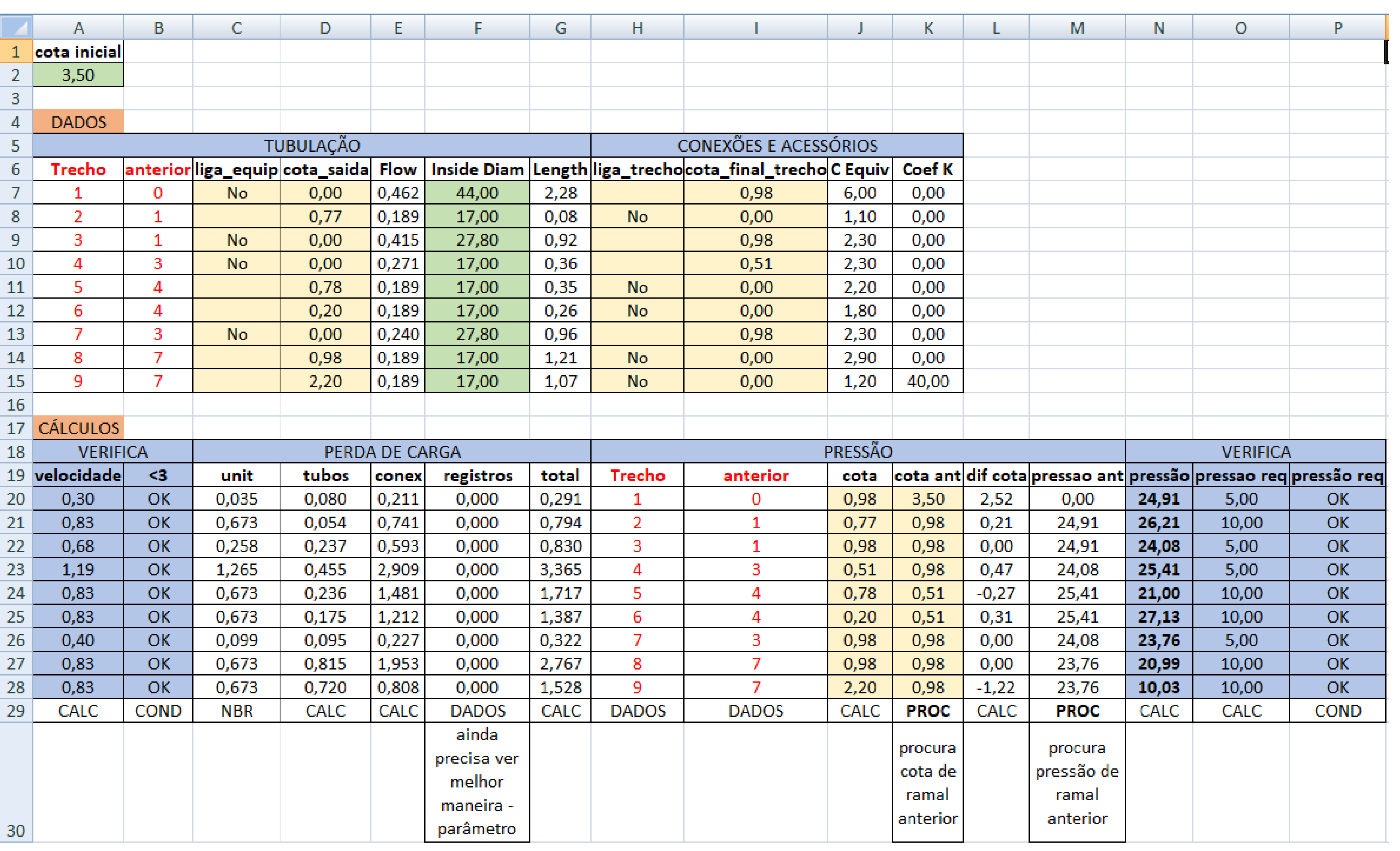

\section{ABRANGÊNCIA}

0 dimensionamento de tubulações é uma das tarefas que já existem no ambiente BIM e que, teoricamente, substituem o procedimento de cálculo tradicional. No entanto, verifica-se que uma das ferramentas mais populares não incorpora efetivamente a norma brasileira a esse respeito. Deparou-se com diversas alternativas de adaptação e destacou-se a possibilidade de harmonização da ferramenta mais popular com a norma brasileira, voltando-se especialmente para 0 ambiente didático. Esse caminho foi empreendido e, como resultado, foram desenvolvidos procedimentos $\mathrm{e}$ instrumentos de apoio à aula. Testes de compatibilização da proposta com a norma NBR 5626 demonstraram-se plenamente satisfatórios e sua aplicação em aula demonstrou-se prática embora ainda sejam necessários ajustes para tornar a proposta mais robusta, já que pequenos erros de modelagem ainda impedem 0 avanço dos alunos.

\section{COMPETÊNCIAS DESENVOLVIDAS}

Foram incluídos alguns parâmetros nas famílias de objetos e desenvolvida uma rotina de programação em Dynamo para realizar a coleta de dados do modelo e passar para uma planilha eletrônica. Dessa forma, 0 aluno percebe o modelo como uma fonte de dados e que permite o trabalho interativo, desde que 0 modelo seja realizado corretamente.

Figura 2: Rotina final do código em Dynamo para fazer o cálculo segundo a NBR 5626

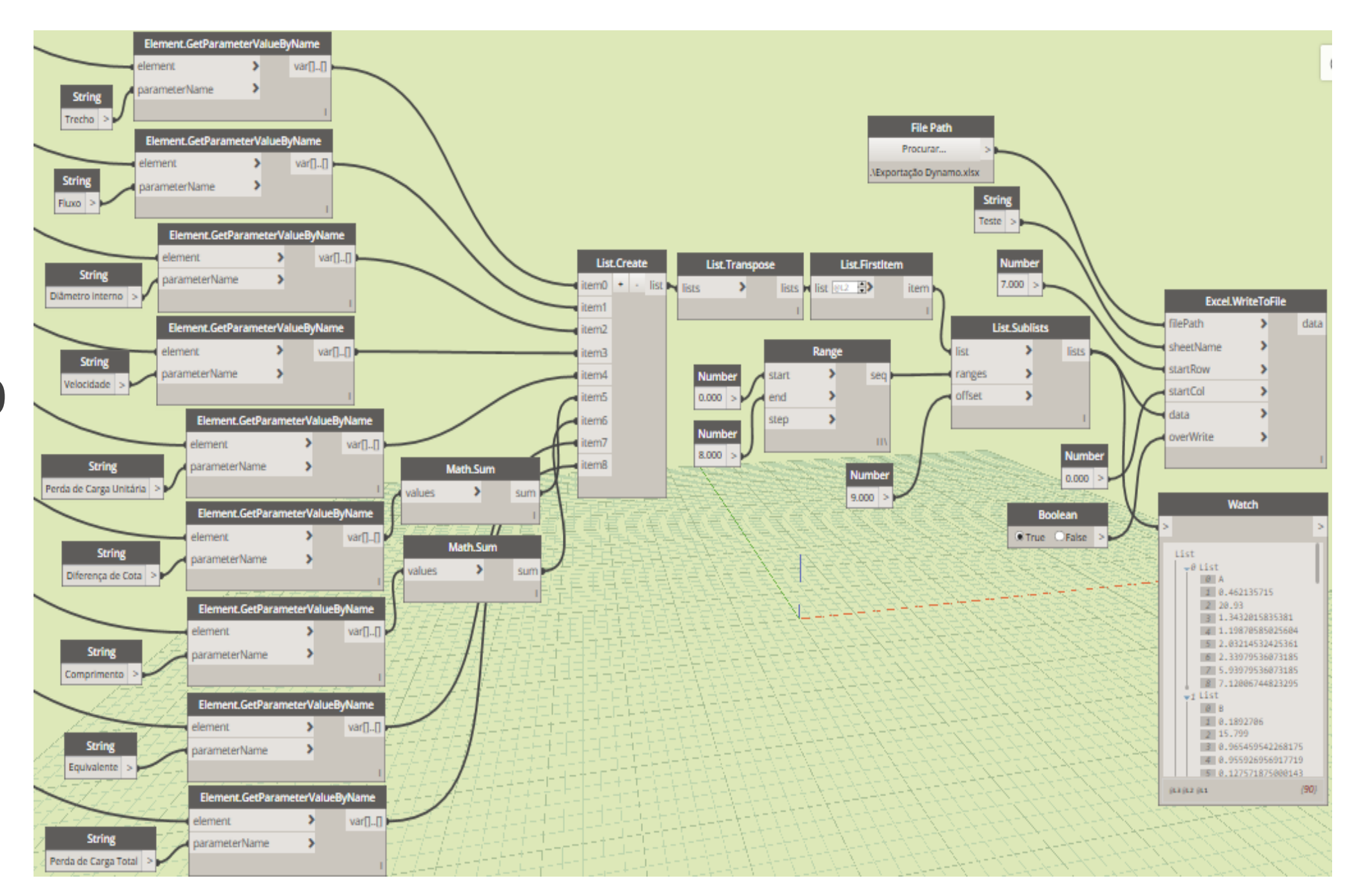

Sérgio Leal Ferreira1

1- Universidade de São Paulo (USP), sergio.leal@usp.br

\section{INTRODUÇÃO}

Como forma de dar continuidade à prática de projeto com o auxílio de ferramentas BIM no curso de Engenharia Civil da USP, procurou-se aproveitar a oportunidade de criação de disciplina eletiva para alunos de quarto e quinto anos de modo a incluir um aprofundamento e maior detalhamento na modelagem voltada para o projeto de instalações hidráulicas. A primeira dificuldade foi que a disciplina não poderia exigir pré-requisitos, ou seja, 0 aluno poderia chegar sem ter tido contato com as disciplinas correspondentes de Introdução ao Projeto (onde se tem contato com 0 conceito e ferramentas BIM) e a disciplina de Instalações Prediais I (onde se tem contato com o projeto de água fria e respectivo dimensionamento). Outras dificuldades se apresentaram relacionadas ao dimensionamento seguindo a norma brasileira e uma forma de superar essa dificuldade será apresentada aqui.

\section{AGRADECIMENTOS}

Agradecimento à USP que proporcionou uma bolsa ao aluno Thiago Turri que, por sua vez, cooperou decisivamente para 0 desenvolvimento desse material, e também à profa. Lúcia Helena de Oliverira que ajudou a orientar e revisou 0 trabalho. 